\title{
Crossed renal ectopia with an unusual form of fusion (inverted $U$ shape) managed by novel approach - laparoscopic ureterocalicostomy. A case report
}

\author{
Osama Bani Hani ${ }^{1 *}$, Omar Halalsheh ${ }^{1}$, Yazeed Mohammad ${ }^{1}$, Anas Bani Yaseen ${ }^{1}$, \\ Ruba Khasawneh ${ }^{2}$, Nour Al-Sheikh ${ }^{2}$, Mais Al-Khalili ${ }^{3}$, Mohannad Mahmoud Alomari ${ }^{1}$ \\ ${ }^{1}$ JORDAN UNIVERSITY OF SCIENCE \& TECHNOLOGY, DEPARTMENT OF UROLOGY, KING ABDULLAH UNIVERSITY HOSPITAL, IRBID-JORDAN \\ ${ }^{2}$ JORDAN UNIVERSITY OF SCIENCE \& TECHNOLOGY, DEPARTMENT OF RADIOLOGY, KING ABDULLAH UNIVERSITY HOSPITAL, IRBID-JORDAN \\ ${ }^{3}$ MINISTRY OF HEALTH, DEPARTMENT OF COMMUNITY MEDICINE, AMMAN-JORDAN
}

\section{ABSTRACT}

Herein we present a case of crossed renal ectopia with an unusual type of fusion, discovered incidentally in a 11-year-old girl presented with recurrent urinary tract infections. Both kidneys were located on the right side of the body fused in their upper poles only, forming an inverted $U$ shape.

After reviewing the published data on this topic, we found that most of the described anomalies were within the six well-known types of fusion anomalies. This child had an unusual clinical presentation of severe hydronephrosis of the orthotopic kidney. A unique surgical technique to correct the pathology to be able to preserve the residual mass of that kidney was performed.

\author{
Category: Case Presentation \\ Received: January 20, 202 \\ Accepted: March 22, 2021 \\ Published: May 10, 2021 \\ Keywords: \\ crossed renal ectopia, laparoscopic ureterocalicostomy \\ *orresponding author: \\ Osama Bani Hani, \\ Jordan University of Science \& Technology, Department of \\ Urology, King Abdullah University Hospital, Irbid-Jordan \\ E-mail: osbanihani@yahoo.com
}

\section{Introduction}

Crossed fused renal ectopia is a rare congenital malformation with a prevalence of 1 in 1000 live births or even less, with an incidence at autopsy of 1 in 2000. There is a slight male predominance (3:2), and left - to - right crossover occurs more frequently than its counterpart [1]. The anomaly is associated with many malformations involving the genitourinary system such as vesicoureteral reflux (VUR), ureteropelvic junction (PUJ) obstruction, and cystic dysplasia, all these in addition to other extraurinary malformations in the gastrointestinal, skeletal, and cardiovascular systems [2].

Both kidneys are located on one side of the midline and fused in different formations, as described by many authors in the literature. The six well-known forms of fusion are: inferior and superior fusions, $S$ shape or sigmoid, lump, disc, and L-shape kidney (Figure 1), with the inferior fusion being the most commonly reported variety [3]. In our case, we came across an unusual form of fusion that wasn't described previously, which was seen on CT scan radiological evaluation as a pre-surgical evaluation. This was seen in an 11-year-old female patient who presented initially with febrile urinary tract infection (UTI) at the age of 5 years, and was found to have left - to - right crossed fused renal ectopia with mild bilateral hydronephrosis.

She was diagnosed to have voiding dysfunction and was initiated on conservative measures. But she presented later (at the age of 11 years) with repeated attacks of right loin pain and fever. So, re-evaluation revealed severe hydronephrotic right kidney caused by external compression on the upper right ureter by the lower portion of the ectopic left kidney, with fusion in-between the two kidneys in upper poles only creating an inverted $\mathrm{U}$ shape renal fusion. In this case, we discuss the presentation, diagnosis, management, and outcome of this rare renal anomaly. 

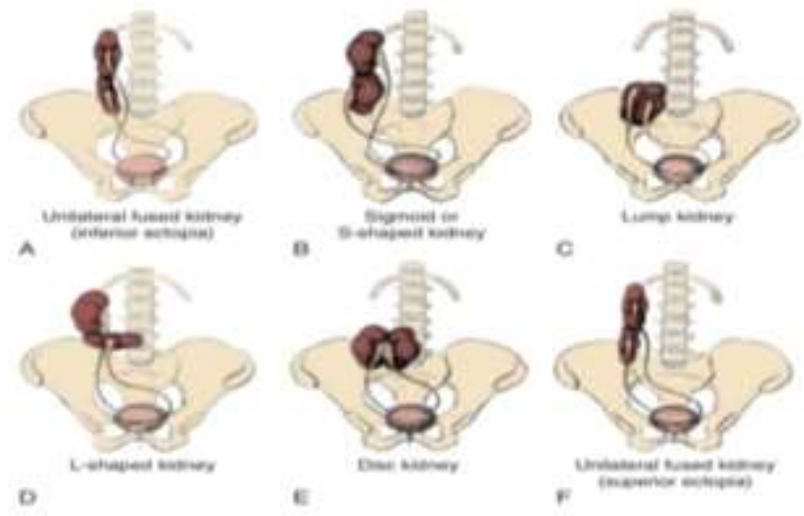

Figure 1: A-F. This figure shows the most commonly reported form of fusion, with type A being the most common while type $\mathrm{F}$ is the least common. Note that, in all cases of fusion, each ureter intersects the bladder in its orthotopic position.
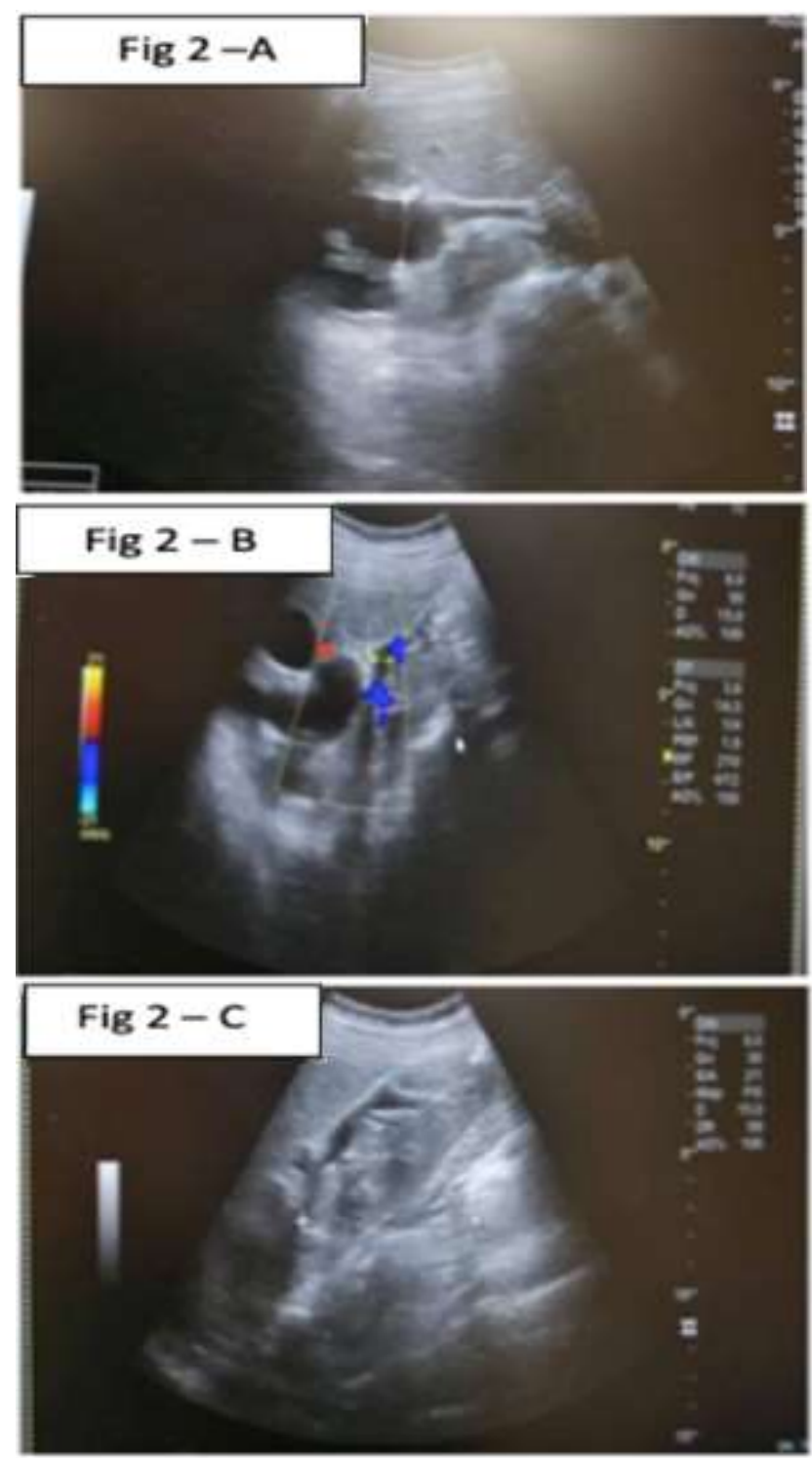

Figure 2: A-C. Ultrasonography of the kidneys.

A. Marked right sided hydronephrosis

B. Dilatation of proximal right ureter

C. Left kidney with no hydronephrosis

\section{Case presentation}

An 11-year-old female patient presented to our pediatric urology clinic complaining of recurrent attacks of right loin pain and febrile UTIs. This was after 6 years of close follow-up for her initial presentation of lower urinary tract symptoms and afebrile UTI. She was investigated and found to have a positive urine culture treated by oral antibiotics. Subsequently, she again presented another proven UTI, and the urinary tract ultrasound (UUS) revealed that both kidneys are located on the right side of the body with mild bilateral hydroureteronephrosis.

Voiding cystourethrogram (VCUG) was performed and showed smooth looking bladder without vesicoureteral reflux. As the child was suffering from chronic constipation, the diagnosis was bladder-bowel syndrome and was instructed on a conservative management plan. Unfortunately, she presented later at the age of 11 years with recurrent febrile right pyelonephritis. Her UUS showed severe hydronephrosis of the right (customarily located) kidney with the dilated upper ureter. No hydronephrosis of ectopic left fused kidney was detected (Figure 2: A-C).

Subsequently, VCUG and nuclear imaging (MAG3) were done for further assessment (Figure 3). VCUG showed no vesicoureteral reflux on either side, and MAG3 showed normally functioning crossed left kidney with preserved function and no hydronephrosis. The right kidney was poorly functioning and with non-obstructed (delayed) hydronephrosis.

Diagnostic cystourethroscopy and bilateral retrograde pyelogram were performed, showing normal-looking bladder and trigone with both ureteric orifices located on their normal orthotopic anatomical positions (Figure 4). Retrograde bilateral pyelograms showed severely dilated right renal pelvis caused by external compression on the proximal right ureter by the crossed left kidney, so the right double $\mathrm{J}$ stent was inserted.

Computed tomography with IV contrast (CT scan) was performed and showed left-to-right crossed renal ectopia. A fusion of the upper poles only with marked compression of the crossed kidney on the proximal ureter of the orthotopic kidney (creating severe right hydronephrosis) was noted, and right $\mathrm{JJ}$ stent in situ (Figure 5). Both renal vasculatures were normally distributed, in addition to the extra-renal arterial branch arising from the right renal artery to the upper pole of the left crossing kidney. The lower pole of the left kidney was supplied by left renal artery (Figure 6). 


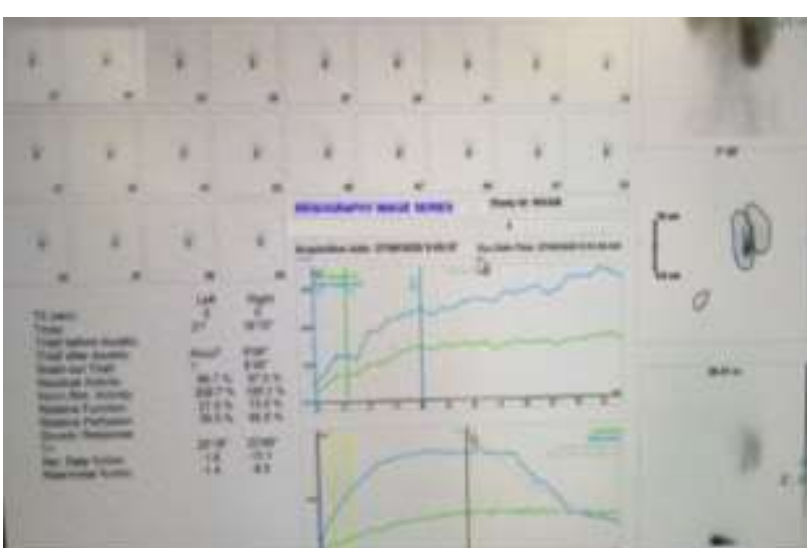

Figure 3. The diuretic renography. (MAG3) shows that there is an evidence of delayed contrast excretion on the right side and marked decrease in relative function, $27 \%$.

*Blue-upper-curve = right kidney

*Green-lower-curve = left kidney
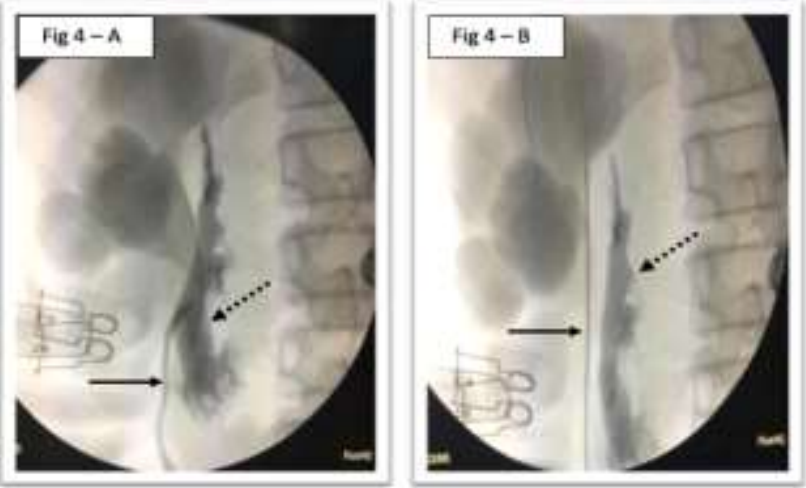

Figure 4: A-B. The bilateral retrograde pyelogram shows the external compression exerted on the right proximal ureter (PUJ area) by the left crossed kidney (A), and the right ureteric stent insertion (B).

* straight arrow $=$ right ureter

*broken arrow $=$ left ureter
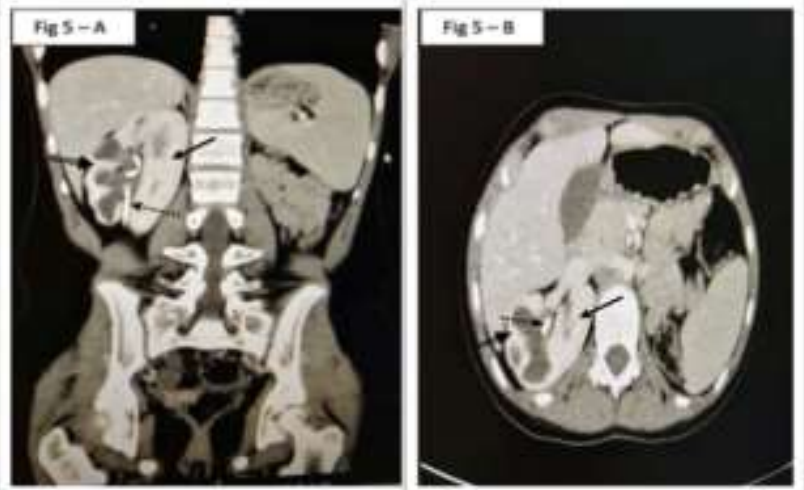

Figure 5: A-B. An enhanced CT scan of the abdomen and pelvis which shows the unusual fusion between both kidneys (upper poles only fusion or inverted $\mathrm{U}$ shape fusion). $\mathrm{A}$ is the coronal view and $\mathrm{B}$ is the axial view.

Double-line arrows = right kidney;

One-line arrows = left kidney;

Broken arrow $=$ DJ stent
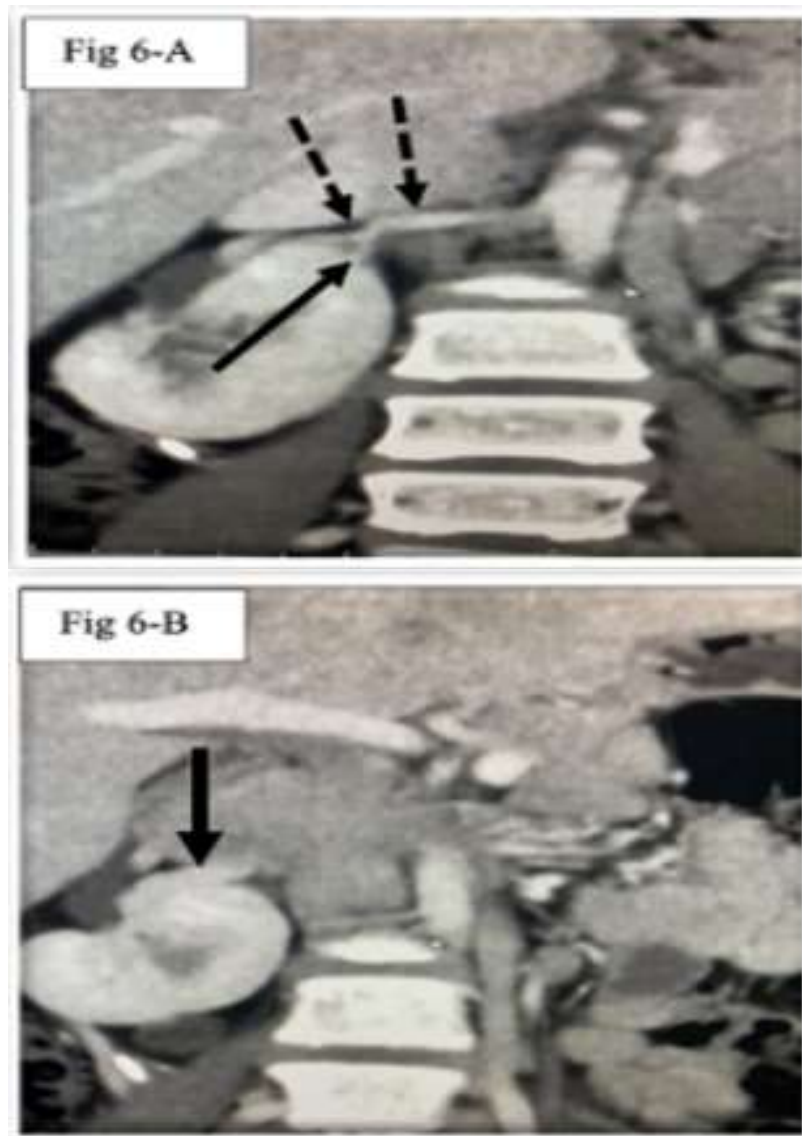

Figure 6-A. Broken arrows represent the right renal artery; the straight arrow represents a small branch that arises from the right renal artery and supplies the upper pole of the left kidney.

Figure 6-B. The arrow represents the left renal artery that supplies the lower portion of the left kidney.

Later, the patient underwent a laparoscopic right ureterocalicostomy (Figure-7). Thus, the right ureter was mobilized away from the compressing ectopic left lower pole of the kidney, and re-anastomosed to the most dependent atrophic lower pole of the right kidney with interrupted $4 / 0$ vicryl stitches over $4.8 / 20 \mathrm{~cm} \mathrm{JJ}$ stent.

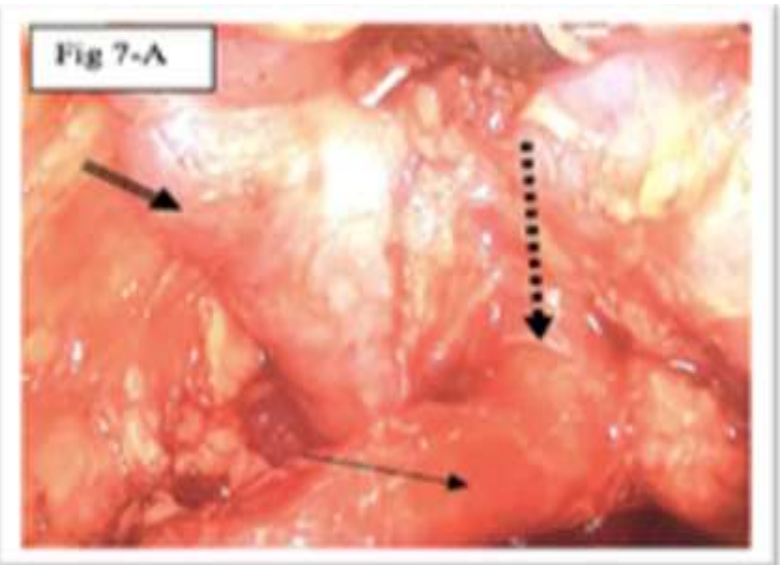

Figure 7-A. The anatomy of the right kidney after completing dissection, straight arrow represents the right ureter, Broken arrow represents right renal pelvis and the Double line arrow represents right lower calyx. The left kidney is not visible because it was retracted away. 


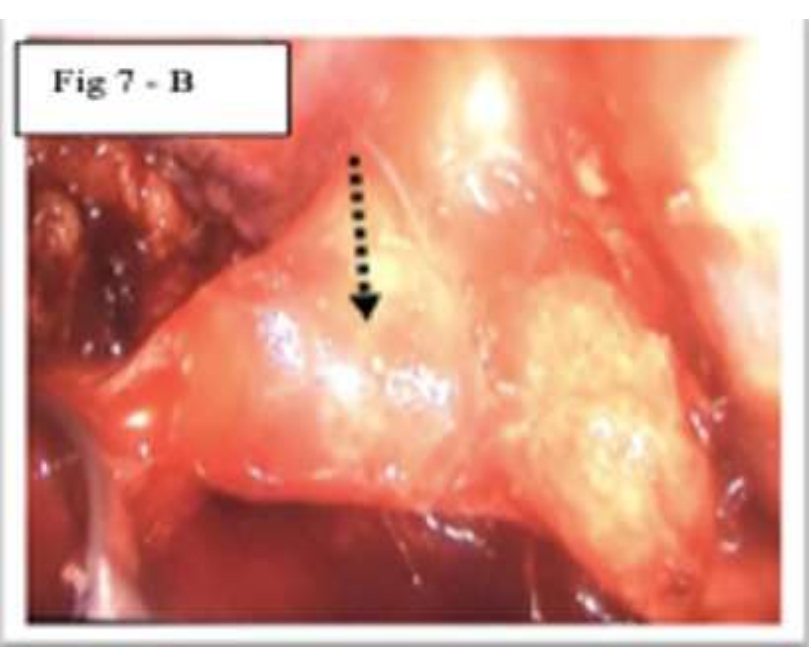

Figure 7-B. This image shows the right renal pelvis (Broken arrow) after complete dissection.

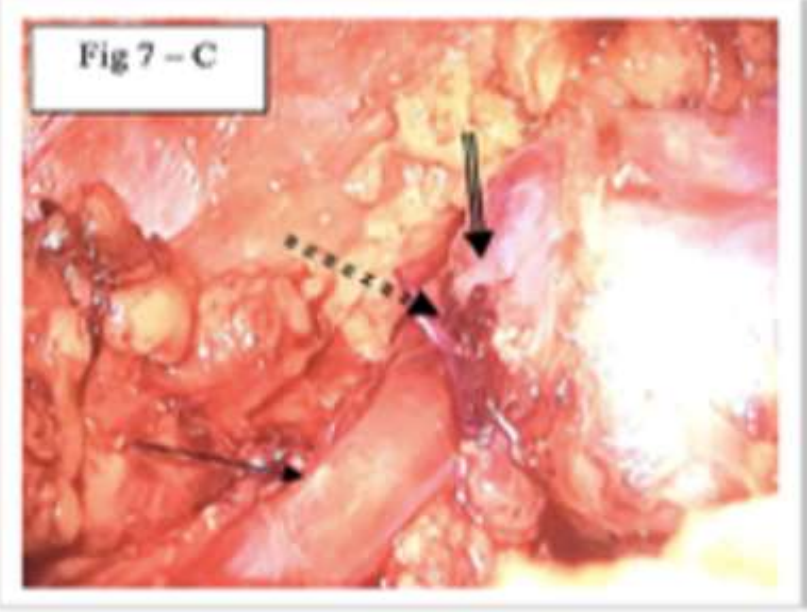

Figure 7-C. This image shows the right lower ureterocalicostomy after completing anastomosis, in which the right ureter (Straight arrow) was connected to the right lower calyx (Double-line arrow) in tension free, watertight anastomosis over the JJ stent. The Double-line Broken arrow represents the site of anastomosis.

The surgical time was about 100 minutes, with no documented complications, a smooth recovery period, no significant events, and two days of hospitalization. The stent is expected to be removed after a few weeks.

\section{Discussions}

Crossed renal ectopia is a relatively uncommon congenital kidney anomaly; in $90 \%$ of cases, the crossed kidney fuses with the orthotopic kidney. There are six types of fusion that have been already described in Introduction (Figure-1, A-F). In the present case, the fusion occurred in an unusual form (only upper pole or inverted $U$ shape fusion, an incomplete disc fusion), and to the best of our knowledge, this is a unique type of crossed renal ectopia with fusion. This form of fusion was associated with a complication related to the crossed kidney's anatomic position, which has led to the compression of the proximal right ureter. As a result, the orthotopic kidney had irreversible changes with a marked reduction of its function.

Patient diagnosed with crossed fused renal ectopia are generally asymptomatic. They are usually diagnosed accidentally during investigations for nonspecific urological symptoms. The most commonly used is ultrasound of the abdomen and pelvis, which is often useful in urological evaluation or other associated abnormalities $[3,4]$. Sometimes patients might present with loin pain, hematuria, urinary tract infection, or symptoms related to the associated anomalies.

Associated renal abnormalities are variable, such as VUR, which is most common, in addition to PUJO in the ectopic kidney and hypoplastic or dysplastic ectopic kidney [5, 6], and rarely even the formation of kidney stones [7]. The increased possibility of associated renal abnormalities underscores the importance of extensive urological evaluation and long-term follow-up for affected children.

Patients with asymptomatic cross-renal ectopia and no biochemical or radiological evidence of renal failure or even kidney impairment do not require surgery. However, when surgery is indicated, comprehensive and thorough imaging such as contrast enhanced CT or MRU should be performed. These investigations are able to clarify the exact anatomy of renal pathology, the type of fusion and to assess the vascularity that tends to be abnormal in most cases [8].

Different surgical options were suggested to correct the associated anomalies, such as ureteric reimplantation, dismembered pyeloplasty, pelvi-pelvostomy, and different laparoscopic surgical procedures $[9,10]$. To the best of our knowledge, laparoscopic ureterocalicostomy, as performed in this case, was not previously reported.

Usually, these patients need regular follow up for the possibility of renal disorders, especially for the ectopic kidney [3,11]. Such investigations include measurement of the total and split renal function, proteinuria and blood pressure [12], which did not apply in our case where the injury was to the orthotopic normally located right kidney.

\section{Conclusions}

Crossed renal ectopia with fusion is a rare congenital anomaly that is usually clinically silent and does not require intervention. But it can also become symptomatic with long-term clinical sequelae, which requires prompt diagnosis and management. It may also be present in an unusual form other than those mentioned in the literature, such as only the upper poles or the inverted U-shaped fusion. Laparoscopic ureterocalicostomy may be a good option in such cases, with satisfactory long-term results and safety. 


\section{Conflict of interest disclosure}

There are no known conflicts of interest in the publication of this article. The manuscript was read and approved by all authors.

\section{Compliance with ethical standards}

Any aspect of the work covered in this manuscript has been conducted with the ethical approval of all relevant bodies and that such approvals are acknowledged within the manuscript.

\section{References}

1. Wein AJ, Kavoussi LR, Partin AW, Peters CA. (2016). Campbell-Walsh Urology. Eleventh edition. Philadelphia, PA: Elsevier Saunders.

2. Cook WA, Stephens FD. Fused kidneys: morphologic study and theory of embryogenesis. Birth Defects Orig Artic Ser. 1977;13(5):327-40.

3. Loganathan AK, Bal HS. Crossed fused renal ectopia in children: a review of clinical profile, surgical challenges, and outcome. $J$ Pediatr Urol. 2019;15(4):315-321. doi: 10.1016/j.jpurol.2019.06.019

4. Goodman JD, Norton KI, Carr L, Yeh HC. Crossed fused renal ectopia: sonographic diagnosis. Urol Radiol. 1986;8(1):13-6. doi: 10.1007/BF02924064

5. Arena F, Arena S, Paolata A, Campenni A, Zuccarello B, Romeo G. Is a complete urological evaluation necessary in all newborns with asymptomatic renal ectopia? Int J Urol. 2007;14(6):491-5. doi: 10.1111/j.1442-2042.2007.01764.x

6. Dogan CS, Dorterler ME, Aybar MD, Ciftci H, Gulum M, Akin Y, Yeni E. Associated anomalies and clinical outcome in children with ectopic kidney. Saudi $J$ Kidney Dis Transpl. 2017;28(2):330-335. doi: 10.4103/1319-2442.202787

7. Ghosh BC, DeSantis M, Kleyner Y, Zak Y. Crossed fused renal ectopia with calculi. J Am Coll Surg. 2008; 206(4):753. doi: 10.1016/j.jamcollsurg.2007.07.047

8. Türkvatan A, Olçer T, Cumhur T. Multidetector CT urography of renal fusion anomalies. Diagn Interv Radiol. 2009;15(2):127-34.

9. Muruganandham K, Kumar A, Kumar S. Laparoscopic pyeloplasty for ureteropelvic junction obstruction in crossed fused ectopic pelvic kidney. Korean J Urol. 2014;55(11):764-7. doi: 10.4111/kju.2014.55.11.764

10. Modi P, Goel R, Dodia S. Case report: laparoscopic pyeloplasty with pyelolithotomy in crossed fused ectopia. $J$ Endourol. 2006;20(3):191-3. doi: 10.1089/end.2006.20.191

11. Calisti A, Perrotta ML, Oriolo L, Ingianna D, Miele V. The risk of associated urological abnormalities in children with pre and postnatal occasional diagnosis of solitary, small or ectopic kidney: is a complete urological screening always necessary? World J Urol. 2008;26(3):281-4. doi: 10.1007/s00345-008-0249-0

12. van den Bosch CM, van Wijk JA, Beckers GM, van der Horst HJ, Schreuder MF, Bökenkamp A. Urological and nephrological findings of renal ectopia. J Urol. 2010;183(4):1574-8. doi: 10.1016/j.juro.2009.12.041

13. Simonds E, Iwanaga J, Kikuta S, Schumacher M, Dupont G, Altafulla J, Yilmaz E, Oskouian RJ, Tubbs RS. Case Report of a Pelvic Crossed Fused Renal Ectopic Kidney. Kurume Med J. 2020;66(1):55-58. doi: 10.2739/kurumemedj.MS661004 